\title{
Follicle development and oocyte maturation during the immediate preovulatory period in Meishan and white hybrid gilts
}

\author{
L. S. Faillace and M. G. Hunter* \\ Department of Physiology and Environmental Science, Faculty of Agricultural and Food Sciences, \\ University of Nottingham, Sutton Bonington Campus, Leics LE12 5RD, UK
}

\begin{abstract}
A study was carried out to compare preovulatory ovarian events in prolific Meishan gilts (which have high levels of embryo survival) with contemporary white hybrid control gilts. Gilts of similar reproductive ages (second or third oestrous cycle) were observed three times a day for oestrous behaviour and ovaries recovered at a time estimated as within $7 \mathrm{~h}$ of ovulation (white hybrid, $n=13$; Meishan, $n=16$ ). Preovulatory follicles were recovered ( $n=195$, white hybrid; $n=252$, Meishan), and oocytes were aspirated and fixed for later identification of meiotic stage, and follicular fluid was frozen for subsequent determination of progesterone. The number of presumed ovulatory follicles recovered per animal was similar to the expected ovulation rate (15.0, white hybrid; 15.75, Meishan; $P>0.1$ ); however, follicles from Meishan gilts were smaller $(8.1$ versus $9.0 \mathrm{~mm}, P<0.001)$ and contained less follicular fluid $(139.9$ versus $187.6 \mu \mathrm{l}, P<0.02)$ than did white hybrid gilts. Total follicular progesterone (88.7 ng per follicle, white hybrid; $77.4 \mathrm{ng}$ per follicle, Meishan) and concentration of progesterone in follicular fluid $\left(526 \mathrm{ng} \mathrm{ml}^{-1}\right.$, white hybrid; $640 \mathrm{ng} \mathrm{ml}^{-1}$, Meishan) did not differ between the two breeds $(P>0.1)$. There were no breed differences in the extent of heterogeneity in follicular diameter, volume of follicular fluid, and total follicular progesterone and progesterone concentration $\langle P>0.1)$. However, classification of recovered oocytes into seven discrete meiotic stages revealed that more oocytes recovered from Meishan preovulatory follicles were in the more advanced stages of meiosis than were those recovered from white hybrid gilts $(P<0.001)$. In conclusion, it is suggested that the advanced oocyte maturation in follicles of Meishan pigs before ovulation may be important for ensuring the prolificacy of this breed.
\end{abstract}

\section{Introduction}

Embryonic mortality continues to be a major cause of economic loss in the swine industry and is probably a direct result of less developed embryos being disadvantaged by their asynchronous presence in a uterine environment advanced by more mature embryos (Anderson, 1978; Pope et al., 1986, 1990; Pope, 1992). The presence of a heterogeneous population of embryos within the uterus probably results from variability in the processes of folliculogenesis, oogenesis or ovulation. There is considerable heterogeneity in the morphology and biochemical development of preovulatory porcine follicles (Grant et al., 1989; Hunter et al., 1989). This follicular heterogeneity results in the more developed follicles in the preovulatory population giving rise to oocytes at more advanced stages of maturation and subsequently more mature zygotes (Xie et al., $1990 a, b, c)$.

It has been suggested that the high prolificacy and low embryonic mortality of Meishan pigs is partly explained by reduced variation in ovarian activity (Hunter et al., 1992).

*Reprint requests.

Received 28 October 1993.
However, recent investigations into characteristics of preovulatory follicles recovered immediately before the onset of behavioural oestrus in Meishan and white hybrid gilts found that there was considerable heterogeneity in the population of follicles from both breeds (Biggs et al., 1993). Nevertheless, there was a higher concentration of oestradiol in the follicular fluid of Meishan gilts compared with that of white hybrid gilts, suggesting that the population of follicles in Meishan gilts were at a more advanced stage of biochemical development than were those of white hybrid gilts. The interaction between the intrafollicular environment and the oocyte is complex and recent evidence suggests that follicles at more advanced stages of maturity have beneficial effects on oocyte maturation and subsequent early embryo development (Ding and Foxcroft, 1992). Terqui et al. (1992) reported that zygotic development was more advanced and conceptus development more uniform in Meishan pigs than in European breeds (Bazer et al., 1988a), which supports the contention that follicular development, oocyte maturation or ovulatory pattern in Meishan pigs is more advanced or synchronous. This hypothesis is strengthened further by the finding that the duration of the ovulatory process is shorter in Meishans than in European breeds (Terqui et al., 1990). The objective of the present 
investigation was therefore to examine the maturational status of follicles and oocytes in the immediate preovulatory period from Meishan and white hybrid gilts to determine whether there are differences in these characteristics between breeds.

\section{Materials and Methods}

\section{Animals}

Sixteen prepubertal Meishan (approximately 70 days of age) and 13 prepubertal white hybrid (Landrace $\times$ (Landrace $\times$ Large White) gilts (approximately 150 days of age) were penned in groups according to breed. Vasectomized boars (of the appropriate breed) were introduced into the pens once a day to stimulate the onset of puberty and to detect oestrus. Approaching the third or fourth oestrus, boars were introduced three times a day (at intervals of $8 \mathrm{~h}$ ) to predict the time of onset of behavioural oestrus more accurately. Ovaries were recovered at $27 \mathrm{~h}$ after the first observation of standing oestrus for the white gilts; at this time all stages of the first meiotic division are represented and there is a spread in the distribution of oocytes in these stages (Xie et al., 1990c; present study). Since white hybrid gilts begin ovulation at $34 \mathrm{~h}$ after the onset of behavioural oestrus (Signoret et al., 1972; Xie et al., 1990c; Wilmut ef al., 1992) and Meishan gilts at $49 \mathrm{~h}$ after the onset of behavioural oestrus (Terqui et al., 1990; Wilmut et al., 1992; Faillace et al., 1994; L. S. Faillace and M. G. Hunter confirmed again in this group of gilts, unpublished observations), the time of recovery of ovaries from Meishan gilts was adjusted to $42 \mathrm{~h}$ after the onset of oestrus. Ovaries from the two breeds were therefore recovered at an exactly equivalent time before the predicted ovulation.

\section{Follicular tissue}

The methods for handling and dissection of ovarian tissue were as reported by Foxcroft et al. (1987) and Biggs et al. (1993). All follicles $\geq 3 \mathrm{~mm}$ diameter were dissected, their diameters recorded and they were examined under a dissecting microscope to locate and recover the oocyte. Follicular fluid was aspirated, measured and placed in $1 \mathrm{ml}$ of Hank's balanced salt solution with 20 mmol Hepes buffer $\mathrm{l}^{-1}$ (ICN Flow Laboratories, High Wycombe, Bucks), which was frozen at $-20^{\circ} \mathrm{C}$ for subsequent determination of progesterone concentration.

Oocytes were isolated using a fine-bore Pasteur pipette and the surrounding cumulus cells dispersed by the addition of $0.1 \%$ hyaluronidase (Sigma Chemical Company Ltd, Poole). Cumulus-free oocytes were mounted, fixed in acetic alcohol ( $1: 3, \mathrm{v}: \mathrm{v})$ for $48 \mathrm{~h}$, stained with Lacmoid (Sigma Chemical Company Ltd, Poole) and examined by phase-contrast microscopy. Classification of the stage of nuclear maturation of the oocytes was assessed as described by Hunter and Polge (1966). The categories for classification were: germinal vesicle, germinal vesicle breakdown, prometaphase, metaphase I, anaphase I, telophase I and metaphase II. Follicles that were clearly atretic (indicated by opaque nonvascular surface and cloudy follicular fluid containing cellular debris; Maxson et al.,
1985) or contained a degenerate oocyte (defined by misshapen plasma membrane and a fragmented germinal vesicle) were eliminated from further study.

\section{Progesterone radioimmunoassay}

Progesterone concentrations in follicular fluid were determined in a direct assay as described by Grant et al. (1989). The limit of sensitivity was $41 \mathrm{pg}$ per tube and the inter- and intra-assay coefficients of variation were $21.5 \%$ and $13.9 \%$, respectively.

\section{Statistical analyses}

All data were analysed using the GENSTAT statistical package (GENSTAT 5 Committee, 1989). Follicular diameter, volume of follicular fluid, total follicular progesterone and concentration of progesterone in follicular fluid were analysed using ANOVA using a statistical model that included breed as treatment and gilt as block structure. The heterogeneity or variance of these same characteristics was compared between breeds by analysis of deviance and, as independently estimated variances were being compared, it was assumed that they followed a gamma distribution (McCullagh and Nelder, 1989; Biggs et al., 1993). Follicular progesterone data were also analysed by multiple regression analysis using a statistical model that included the effect of breed, gilt, the stage of meiotic maturation of the oocyte and the interaction of breed with meiotic stage. The effect of breed was tested for significance using the mean square for the effect of gilt in the variance ratio. Pooled variance estimates for follicle characteristics are reported as standard errors of the difference (SED). Meiotic stage of oocytes was analysed by Chi-square analysis which examined the proportion of gilts in which most of the oocytes were in one of two meiotic stage categories. The meiotic stage category comparisons were: (i) germinal vesicle to telophase I versus metaphase II, (ii) germinal vesicle to metaphase I versus anaphase I to metaphase II and (iii) germinal vesicle to prometaphase versus metaphase I to metaphase II. Comparisons of the proportion of individual oocytes (regardless of gilt) that were at the same meiotic stage categories were also made by Chi-square analysis.

\section{Results}

\section{Numbers and size of follicles}

A total of 447 preovulatory follicles were recovered from the two breeds; seven follicles were rejected as atretic and not destined to ovulate. There was a similar number of preovulatory follicles $(P>0.10)$ per gilt for the two breeds (Table 1). Follicles from Meishan gilts were smaller $(P<0.001)$ and contained less follicular fluid $(P<0.02)$ than did follicles of white hybrid gilts (Table 1). There were no differences between breeds in variances for follicular diameter or volume of follicular fluid $(P>0.10)$. 
Table 1. Characteristics of preovulatory follicles recovered from white hybrid $(n=13)$ and Meishan $(n=16)$ gilts

\begin{tabular}{lcccc}
\hline Follicle characteristic & white hybrid & Meishan & SED & $P$ value \\
\hline Number per gilt & 15.0 & 15.8 & 0.9 & $>0.1$ \\
Diameter (mm) & 9.0 & 8.1 & 0.25 & $<0.001$ \\
Fluid volume $(\mu \mathrm{l})$ & 187.6 & 139.9 & 18.1 & $<0.02$ \\
Progesterone (ng per follicle) & 88.7 & 77.4 & 34.2 & $>0.1$ \\
Progesterone (ng m${ }^{-1}$ fluid) & 526 & 640 & 245 & $>0.1$ \\
\hline
\end{tabular}

SED: standard error of the difference.

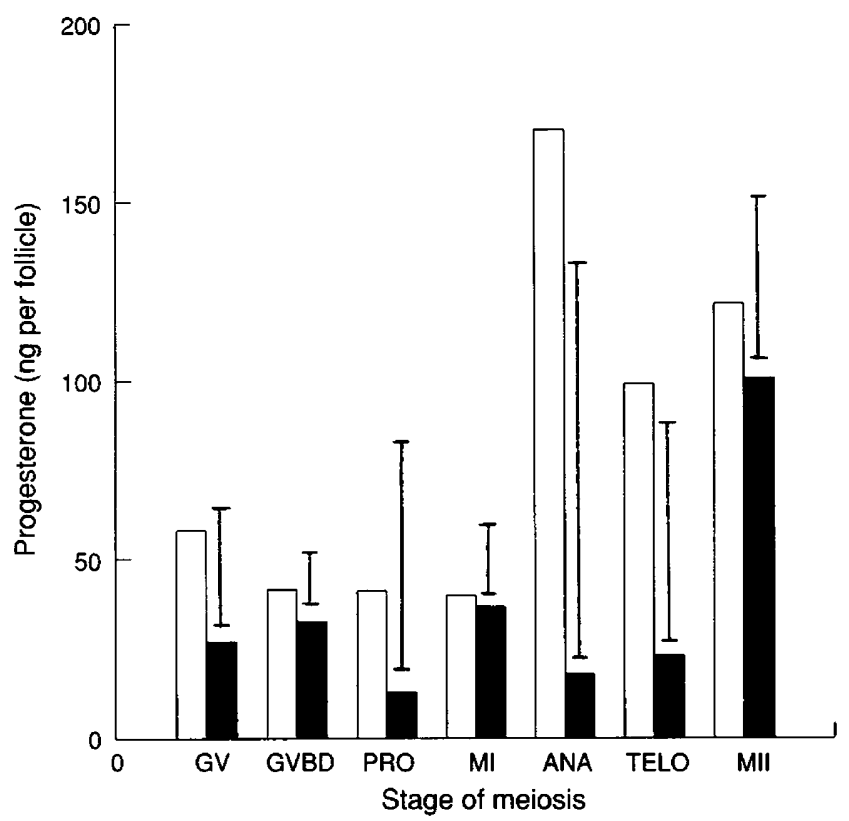

Fig. 1. The relationship between progesterone concentration per follicle and the stage of oocyte meiotic maturation. Means and SED for each of the meiotic stages are shown for follicles from $(\square)$ white hybrid ( $n=13,176$ total follicles) and ( $\square$ ) Meishan ( $n=16,207$ total follicles) gilts. GV: germinal vesicle; GVBD: germinal vesicle breakdown; PRO: prometaphase; MI: metaphase I; ANA: anaphase; TELO: telophase; MII: metaphase II.

\section{Progesterone concentration in follicular fluid}

The amount of progesterone in the follicular fluid was expressed as total content per follicle and as concentration in the follicular fluid. There was much variation and thus progesterone concentration in the follicular fluid was not significantly different between the breeds, whether expressed on a per follicle basis $(P>0.10)$ or as a concentration in the follicular fluid $(P>0.10)$ (Table 1$)$. Variances in concentrations of progesterone in follicular fluid were similar $(P>0.10)$ for the two breeds.

There was a positive relationship $(P<0.001)$ between both total follicular progesterone and concentration of progesterone in follicular fluid and advancing stages of meiotic maturation (Fig. 1). When a regression model including the effects of breed, stage of oocyte maturation and their interaction was used, the relationship between total follicular progesterone and stage of oocyte maturation differed according to breed $(P<0.02)$. However, when the effect of gilt was included in the regression model, that effect was also significant $(P<0.001)$. When the mean square for the effect of gilt was used as the error term to test the effect of breed, the relationship between total follicular progesterone and stage of maturation did not significantly differ according to breed $(P>0.10)$.

\section{Stage of meiotic maturation}

Oocytes were classified into seven meiotic stages, and 383 $(85.7 \%)$ were positively identified. Significantly more of the oocytes of Meishan gilts were at the more advanced meiotic stage categories than were those of white hybrid gilts, regardless of the stage category comparison (Meishan versus white hybrid: $3 / 16$ versus $7 / 13$ in germinal vesicle to telophase and $13 / 16$ versus $6 / 13$ in metaphase II, $P<0.05 ; 1 / 16$ versus $6 / 13$ in germinal vesicle to metaphase $I$ and $15 / 16$ versus $7 / 13$ in anaphase I to metaphase II, $P<0.03 ; 0 / 16$ and $5 / 13$ in germinal vesicle-prometaphase and $16 / 16$ versus $8 / 13$ in metaphase I to metaphase II; $P<0.01$ ). In addition, analysis of all preovulatory oocytes (regardless of the gilts from which they were derived) revealed a similar pattern with a higher proportion of Meishan oocytes in the more advanced meiotic stage categories (Meishan versus white hybrid: 23.8 versus $61.4 \%$ in germinal vesicle to telophase and 76.2 versus $38.6 \%$ in metaphase II, $P<0.001 ; 12.1$ versus $46.6 \%$ in germinal vesicle to metaphase I and 87.9 versus $53.4 \%$ in anaphase I to metaphase II, $P<0.001 ; \quad 3.9$ versus $35.8 \%$ in germinal vesicle to prometaphase and 96.1 versus $64.2 \%$ in metaphase I to metaphase II, $P<0.001$ ). A comparison for the germinal vesicle to metaphase I stage versus the anaphase I to metaphase II stage for both the number of gilts within breed analysis and the total number of oocytes within breed analysis is shown (Fig. 2).

\section{Discussion}

The finding that the predicted ovulation rate (as determined by the number of preovulatory follicles) did not differ between breeds is consistent with previous findings from our laboratory involving Meishan and white hybrid gilts of a similar reproductive age (Biggs et al., 1993; Hunter et al., 1993a). Together with the absence of breed differences, the magnitude of the presumed ovulation rate of the Meishan gilts was compatible 

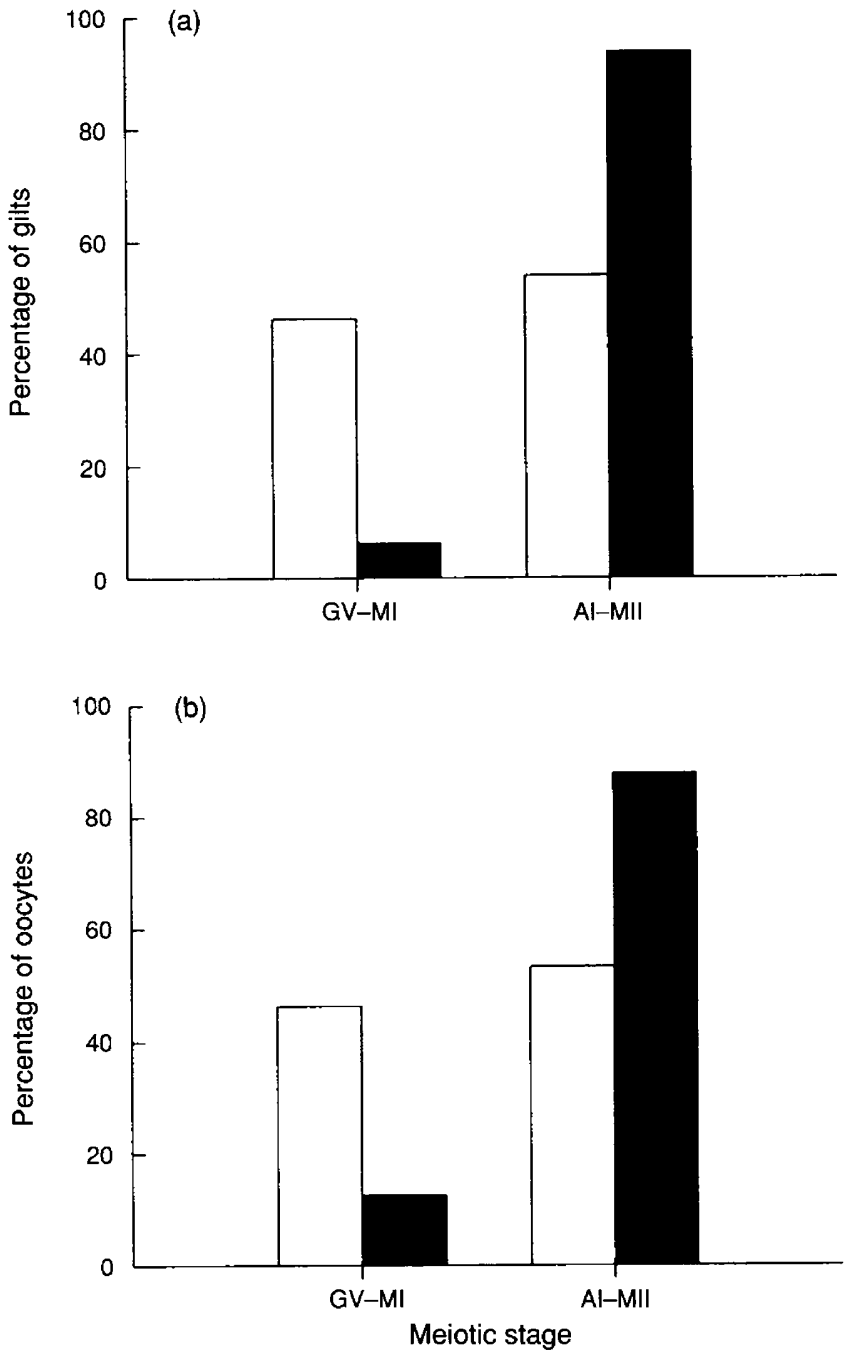

Fig. 2. The percentage of $(\square)$ white hybrid and ( $\square$ ) Meishan (a) gilts (white, $n=13$; Meishan, $n=16$ ) in which most of the oocytes were in one of two meiotic stages and (b) total oocytes (Large White, $n=176$; Meishan, $n=207$ ) that were each of the same two categories. The germinal vesicle to metaphase I (GV-MI) category included germinal vesicle, prometaphase and metaphase I and the anaphase I to metaphase II (AI-MII) category included anaphase I, telophase I and metaphase II. A greater proportion of Meishan gilts $(P<0.03)$ and Meishan oocytes $(P<0.001)$ were in the more advanced category (AI-MI) than were white hybrid gilts and oocytes.

with previous results from gilts of this age (Bazar et al., 1988b; Biggs et al., 1993; Faillace et al., 1994).

The population of oocytes from Meishan gilts was clearly more advanced compared with that of white hybrid gilts. It therefore seems likely that follicles of Meishan gilts, although smaller in size, have an intra-follicular environment that is at a more advanced stage of maturation in terms of the regulatory factors that influence oocyte maturation. Whereas the LH surge is the initial signal for the resumption of meiosis by the oocyte, many follicular factors have been proposed as being involved in the cascade of events that result from that signal. These factors include cAMP, oocyte maturation inhibitor, maturationpromoting factor, glycosaminoglycans, xanthine and adenosine as well as the physical factors of cumulus expansion and granulosa-cumulus uncoupling (see review, Thibault et al., 1987). As the dynamics of the LH surge are the same in Meishan and white hybrid gilts (Hunter et al., 1993a), it is possible that Meishan follicles can respond to the LH surge more effectively, presumably because of their advanced maturity. There is a long interval from the LH surge to germinal vesicle breakdown in pigs relative to most other species (Thibault et al., 1987) and the time from germinal vesicle to germinal vesicle breakdown makes up the greatest proportion of the time to reach metaphase II (Hunter and Polge, 1966; Sato et al., 1978; Xie et al., 1990c); a better response to the surge would therefore probably be involved with mechanisms leading to this stage of meiosis. Furthermore, Xie et al. (1990c) found that over $50 \%$ of the total oocyte population at $27 \mathrm{~h}$ after oestrus was in the early stages of oocyte maturation (germinal vesicle to metaphase I), a similar result to that found in white hybrids in the study reported here. As the interval from germinal vesicle to metaphase II occurs approximately $30 \mathrm{~h}$ after the onset of oestrus (Xie et al., 1990 c), whereas ovulation in European breeds occurs approximately $34 \mathrm{~h}$ after the onset of oestrus (Signoret et al., 1972; Xie et al., 1990c; Wilmut et al., 1992), the development of oocytes that have undergone germinal vesicle breakdown at later stages is likely to be behind at ovulation.

Advanced oocyte maturation in Meishan gilts is particularly interesting as this breed also experiences a prolonged interval between the onset of behavioural oestrus and ovulation (as determined by laparoscopic examination of the ovaries); this interval was calculated as $49 \mathrm{~h}$ (Terqui et al., 1990; Wilmut et al., 1992; Faillace et al., 1994). Hunter et al. (1993a) showed that the LH surge occurs later relative to the onset of oestrus in Meishan than in white hybrid gilts, thereby providing an endocrine basis for the breed difference in time intervals between standing oestrus and ovulation in the two breeds. Furthermore, administration of hCG to Meishan gilts at the time of onset of oestrus significantly reduced the time to ovulation, and to a time interval similar to that in European gilts administered hCG (Faillace et al., 1994). All this evidence, particularly the laparoscopic examination of the ovaries, confirms the validity of the predicted time of ovulation in the Meishan in the study reported here, and thus the accuracy of the comparison of follicles and oocytes between the two breeds. In the unlikely event that an incorrect adjustment was made, this could have potentially had a significant effect on the results obtained. However, regardless of which of the three comparisons of the stage of oocyte maturation was considered, there were always significantly more oocytes from Meishan gilts in the advanced stages of maturation. Although the duration of the metaphase I stage has been reported to be $9 \mathrm{~h}$ (Hunter and Polge, 1966), inclusion of this stage in either the early or the late category did not alter the significant difference in the distribution of oocytes between the breeds.

Oestradiol concentration of follicular fluid is the primary indicator of follicle maturity (Hunter et al., 1992) and our previous findings of enhanced aromatase activity (Hunter et al., 1993b) and higher concentration of oestradiol in follicular fluid (Biggs et al., 1993) in follicles from Meishan gilts, combined with the result of advanced oocyte maturation in Meishan gilts, support the concept that follicles from Meishan gilts are more 
advanced throughout the preovulatory period. The involvement of steroids in the process of oocyte maturation is controversial (Thibault et al., 1987; Ding and Foxcroft, 1992), but it has been demonstrated that a drastic increase in the ratio of progesterone to oestradiol has a severe effect on nuclear maturation in vitro (Osborn et al., 1986). Moreover, the ability of oocytes to undergo male pronuclear formation was positively correlated with concentration of oestradiol in follicular fluid (Ding and Foxcroft, 1992). Despite these findings, it does not appear that intrafollicular steroid conditions are the most important determinant in the ability of oocytes to resume meiosis (Ding and Foxcroft, 1992), but since the concentration of follicular oestradiol probably does indicate the general state of follicle maturity, it is likely to be a good index of the factors that do positively affect oocyte maturation.

The overall mean concentration of follicular progesterone was variable and not different between the breeds. Furthermore, the increase in follicular progesterone with advancing maturity of the oocyte also did not differ between breeds, and overall was similar in pattern to that reported by $X_{i e}$ et al. (1990a). Although the presence of progesterone was found to be necessary for cytoplasmic maturation of the oocyte (Mattioli et al., 1988), low follicular progesterone concentrations did not adversely affect oocyte nuclear maturation (Brzyski et al., 1990). Collectively, these results suggest that follicular progesterone concentration was not a factor that led to advanced maturation for oocytes in Meishan gilts.

Heterogeneity in the follicular population in pigs has been well documented (Foxcroft and Hunter, 1985; Hunter and Wiesak, 1990; Xie et al., 1990a, b, c) and it has been demonstrated that the skewed distribution of oocytes and elapsed period of ovulation is a consequence of variation in the preovulatory follicle population (Pope et al., 1990). Reports of the Meishan having increased uniformity (Bazer et al., 1988a) or rate of blastocyst development (Terqui et al., 1992) and a shorter duration of ovulation (Terqui et al., 1990) led to the hypothesis that increased embryo survival in Meishans may be the direct result of more synchronous follicular growth. Wilmut et al. (1992), however, found no breed differences in either the rate or uniformity of embryo development, while Anderson et al. (1993) and Youngs et al. (1993) reported slower growth and steroid secretion rates for Meishan embryos but found no differences between breeds in the uniformity of embryo development. Our previous study of preovulatory follicles before the time of oestrus (Biggs et al., 1993) combined with our present study of the immediate preovulatory period have also not provided evidence of decreased variability in the characteristics investigated in the population of follicles from Meishan pigs. Whether the Meishan follicle population is more homogeneous in other characteristics or simply more mature requires further study.

In conclusion, as it has been demonstrated that more oocytes have matured through to metaphase II within the $7 \mathrm{~h}$ before ovulation in Meishan than in white hybrid gilts, it is suggested that oocytes of Meishan gilts are of a better quality at ovulation. Taken together with the finding that ovulation occurs later in oestrus (Wilmut et al., 1992; Faillace et al., 1994) and is of shorter duration (Terqui et al., 1990) compared with European breeds, a hypothesis can be developed in which Meishan preovulatory follicles reach maturity earlier in oestrus (before the LH surge) and, therefore, are better able to respond as a group to the LH surge. This results in a population of mature ova which are ovulated over a short duration and fertilized rapidly. The longer oestrous period of the Meishan allows for more matings before ovulation, which helps to ensure that viable spermatozoa in adequate numbers are present at the time of fertilization.

The authors acknowledge the AFRC for financial support. They thank C. Biggs and members of the Joint Animal Breeding Unit for technical assistance and the British Meishan Consortium for the supply of animals.

\section{References}

Anderson LH, Christenson LK, Christenson RK and Ford SP (1993) Investigations into the control of litter size in swine II. Comparisons of morphological and functional embryonic diversity between Chinese and American breeds Journal of Animal Science 71 1566-1571

Anderson LL (1978) Growth, protein content and distribution of early pig embryos Anatomical Record 190 143-155

Bazer FW, Thatcher WW, Martinat-Botte F and Terqui M (1988a) Conceptus development in Large White and prolific Chinese Meishan pigs Journal of Reproduction and Fertility $84 \quad 37-42$

Bazer FW, Thatcher WW, Martinat-Botte F and Terqui M (1988b) Sexual maturation and morphological development of the reproductive tract in Large White and prolific Meishan pigs Journal of Reproduction and Fertility $\mathbf{8 3}$ $723-728$

Biggs C, Tilton JE, Craigon J, Foxcroft GR, Ashworth CJ and Hunter MG (1993) Comparison of follicular heterogeneity and ovarian characteristics in Meishan and Large-White hybrid pigs Journal of Reproduction and Fertility 97 263-269

Brzyski RG, Hofmann GE, Scott IT and Jones HW, Jr (1990) Effects of leuprolide acetate on follicular fluid hormone composition at oocyte retrieval for in vitro fertilization. Fertility and Sterility 54 842-847

Ding JC and Foxcroft GR (1992) Follicular heterogeneity and oocyte maturation in vitro in pigs Biology of Reproduction 47 648-655

Faillace LS, Biggs C and Hunter MG (1994) Factors affecting age at onset of puberty, ovulation rate and time of ovulation in Chinese Meishan gilts Journal of Reproduction and Fertility $100353-357$

Foxcroft GR and Hunter MG (1985) Basic physiology of follicular maturation in the pig Joumal of Reproduction and Fertility Supplement 33 I-19

Foxcroft GR, Shaw HJ, Hunter MG, Booth PJ and Lancaster RT (1987) Relationships between L.H, FSH and prolactin secretion and ovarian function in the weaned sow Biology of Reproduction 36 175-191

Genstat 5 Committee (1989) Genstat 5 Reference Manual. Clarendon Press, Oxford

Grant SA, Hunter MG and Foxcroft GR (1989) Morphological and biochemical characteristics during ovarian follicular development in the pig Journal of Reproduction and Fertility 86 171-183

Hunter RHF and Polge C (1966) Maturation of follicular oocytes in the pig after injection of human chorionic gonadotrophin Journal of Reproduction and Fertility 12 525-531

Hunter MG and Wiesak T (1990) Evidence for and implications of follicular heterogeneity in pigs Journal of Reproduction and Fertility Supplement $\mathbf{4 0}$ $163-171$

Hunter MG, Grant SA and Foxcroft GR (1989) Histological evidence for heterogeneity in the development of preovulatory pig follicles Joumal of Reproduction and Fertility 86 165-170

Hunter MG, Biggs C, Faillace LS and Picton HM (1992) Current concepts of folliculogenesis in monovular and polyovular farm species Journal of Reproduction and Fertility Supplement 45 21-38

Hunter MG, Biggs C, Foxcroft GR, McNeilly AS and Tilton JE (1993a) Comparisons of endocrinology and behavioural events during the periovulatory period in Meishan and Large-White hybrid gilts Joumal of Reproduction and Fertility $97475-480$

Hunter MG, Biggs C and Faillace LS (1993b) Endocrine and follicular studies in Meishan pigs Journal of Reproduction and Fertility Supplement 48 261-270

McCullagh P and Nelder JA (1989) Generalized Linear Models. Chapman and Hall, New York 
Mattioli M, Galeati G and Seren E (1988) Effect of follicular cells during pig oocyte maturation on egg penetrability and male pronuclear formation Gamete Research 20 177-183

Maxson WS, Haney AF and Schomberg DW (1985) Steroidogenesis in porcine atretic follicles: loss of aromatase activity in isolated granulosa and theca Biology of Reproduction 33 495-501

Osborn JC, Moor RM and Crosby IM (1986) Effect of alterations in follicular steroids on the nuclear and cytoplasmic maturation of ovine oocytes Journal of Embryology and Experimental Morphology 98 187-208

Pope WF (1992) Embryogenesis recapitulates oogenesis in swine Proceedings of the Society for Experimental Biology and Medicine 199 273-281

Pope WF, Lawyer MS, Nara BS and First NL (1986) Effect of asynchronous superinduction on embryo survival and range of blastocyst development in swine Biology of Reproduction 35 133-137

Pope WF, Xie S, Broermann DM and Nephew KP (1990) Causes and consequences of early embryonic diversity in pigs Journal of Reproduction and Fertility Supplement 40 251-260

Sato E, Iritani A and Nishikawa (1978) Rate of maturation division of pig follicular oocytes cultured in vitro Japanese Journal of Zootechnical Science 49 $400-405$

Signoret JP, Du Mesnil du Buisson F and Mauleon P (1972) Effect of mating on the onset and duration of ovulation in the sow Journal of Reproduction and Fertility 31 327-330

Terqui M, Bazer FW and Martinat-Botte F (1990) Mechanisms involved in the high prolificacy of the Meishan breed. In Symposium sur le Porc Chinois pp 17-32 Eds N Molenat and C Legault. INRA. Paris
Terqui M, Bazer FW and Martinat-Botte F (1992) Mechanisms of high embryo survival in Meishan gilts. In Proceedings of the International Symposium on Chinese Pig Breeds pp 52-59 Ed. C Runsheng. Northeast Forestry University Press, Harbin

Thibault C, Szollosi D and Gerard M (1987) Mammalian oocyte maturation Reproduction Nutrition and Development 27 865-896

Wilmut I, Ritchie WA, Haley CS, Ashworth CJ and Aitken RP (1992) A comparison of rate and uniformity of development in Meishan and Large White pigs Journal of Reproduction and Fertility 95 45-46

Xie S, Broermann DM, Nephew KP, Ottobre JS, Day ML and Pope WF (1990a) Changes in follicular endocrinology during final maturation of porcine oocytes Domestic Animal Endocrinology 7 75-82

Xie S, Broermann DM, Nephew KP, Geisert RD and Pope WF (1990b) Ovulation and early embryogenesis in swine Biology of Reproduction 43 236-240

Xie S, Broermann DM, Nephew KP, Bishop KD and Pope WF (1990c) Relationship between oocyte maturation and fertilization on zygotic diversity in swine Journal of Animal Science 68 2027-2033

Youngs CR, Ford SP, McGinnis LK and Anderson LH (1993) Investigations into the control of litter size in swine: I. Comparative studies on in vitro development of Meishan and Yorkshire preimplantation embryos Joumal of Animal Science 71 1561-1565 